\title{
O programa narrativo de uma embalagem: análise do Hexagonal Honey
}

The narrative program of a package: Honey Hexagonal analysis

SCHENKEL, Ana; Graduanda em Design Industrial; Universidade do Estado de Santa Catarina ana.schenkel@gmail.com

NUNES, Heloisa; Graduanda em Design Industrial; Universidade do Estado de Santa Catarina heloisa.nunes@hotmail.com

\section{Resumo}

$\mathrm{O}$ artigo tem como objetivo analisar semioticamente a embalagem de mel Hexagonal Honey, produzida pelo designer gráfico russo Maksim Arbuzov. A semiótica de A. J. Greimas foi a base do estudo deste artigo. Essa vertente da semiótica visa analisar o texto como uma totalidade de sentido, ou seja, como um conjunto articulado de elementos e não como partes isoladas. O processo de análise foi dividido em duas partes: o plano de expressão, que passa pela parte de semiótica plástica e figurativa, e o plano de conteúdo, que analisa o texto desde o nível fundamental (mais simples), passando pelo nível narrativo, até chegar ao nível discursivo (mais complexo). O objetivo final deste trabalho é descobrir se essa embalagem tem a capacidade de construir uma narrativa.

Palavras Chave: semiótica; embalagem; hexagonal honey.

\begin{abstract}
The article aims to analyze semiotically the packaging of Hexagonal Honey, produced by Russian graphic designer Maksim Arbuzov. Greimasian semiotics was the basis of the study of this article, this part of semiotics aims to analyze the whole text, without analyzing only its parts separately. The analysis process was divided into two parts: the expression plane, which goes through the part of plastic and figurative semiotics, and the content plane, which analyzes the text from the fundamental (simpler) level, through the narrative level, to reach the discursive (more complex) level. The final objective of this work is to find out if this packaging has the capacity to construct a narrative.
\end{abstract}

Keywords: semiotics; packaging; hexagonal honey. 


\section{Introdução}

Neste trabalho será analisada uma embalagem conceitual de mel produzida pelo designer gráfico russo Maksim Arbuzov no ano de 2013 para o portfólio pessoal. Para tanto, será realizada uma análise semiótica utilizando, como abordagem teórico-metodológica, a semiótica greimasiana e tendo uma questão final a responder: será que uma embalagem é capaz de construir uma narrativa?

A embalagem tem como função principal proteger e estender o prazo de vida do produto que envolve, podendo armazenar este individualmente ou agrupado com outras unidades (PELLEGRINO, 2017). Além disso, há uma função mais subjetiva e igualmente importante, que é a de vender silenciosamente o produto que está em uma loja ou supermercado, rodeado por concorrentes. De acordo com Pellegrino (2017), o consumidor é fortemente influenciado no momento da compra pela embalagem, ou seja, a embalagem precisa chamar a atenção e passar a mensagem certa para quem está comprando. Por este motivo uma análise semiótica de um objeto tão presente no cotidiano de todos é de grande relevância, já que muitas vezes não pensamos em que sentidos são construídos pela embalagem em sua relação com o consumidor.

A semiótica é o estudo do fenômeno da significação ou do signo (tudo aquilo que significa). De acordo com Lucia Santaella (1989, apud RAMALHO, 2005, p.38), a semiótica é uma "ciência que tem por objetivo de investigação todas as linguagens possíveis, ou seja, que tem por objetivo o exame dos modos de construção de todo e qualquer fenômeno de produção de significação e de sentido". Semiótica também pode ser definida, de acordo com Odin, citado por Ramalho (2005, p. 38), como teoria geral dos sistemas de comunicação, capaz de possibilitar o estudo do conjunto dos processos de produção de sentidos, seja intervindo nas linguagens verbais, não-verbais ou no mundo natural

Esta ciência ou área de estudo apresenta no Brasil três escolas de maior abrangência: a semiótica americana, ou peirceana; a semiótica russa, ou da cultura; e a semiótica francesa, ou greimasiana.

De acordo com Ramalho (2005, p.41) a semiótica russa iniciou na metade do século XIX e durou até Stalin entrar ao poder. "Em 1970, a nova geração de semioticistas passa a denominar Semiótica da Cultura a linha específica adotada por eles pelo fato de terem como princípio investigar os sistemas de signos sempre levando em conta seu respectivo contexto cultural." (RAMALHO, 2005, p. 42)

De acordo com Ramalho (2005, p. 42) outra das três escolas, é a semiótica americana, ou semiótica de Peirce, onde criou uma teoria dos signos associado a lógica, que tinha a função de classificar os tipos de signos. Para descrever cada signo, Peirce criou três categorias e criou três palavras para designar essas categorias, primeiridade, secundidade e terceiridade.

A semiótica francesa foi fundada pelo suíço Ferdinand Saussure e, de acordo com Ramalho (2005, p. 45), é conhecida por se desenvolver como dinastias, já que é adotada e utilizada de diversas formas por diferentes cientistas e a partir disso são passadas para seus seguidores. Alguns nomes importantes são: Roland Barthes, Hjelmslev e A. J. Greimas, sendo este um dos semioticistas que se mantiveram mais fiéis às ideias estruturalistas de Saussure (RAMALHO, 2005, p. 46)

A. J. Greimas criou o grupo de pesquisa semio-linguística e é considerado o "pai" da semiótica discursiva que trata o texto como a totalidade de sentido, sendo o texto qualquer totalidade de sentido acabada, desde um texto literário até um objeto de arte.

Tomando, assim, o texto como objeto de significação, a semiótica se preocupa em estudar 
os mecanismos que o engendram, que o constituem como um todo significativo. Em outras palavras: procura descrever e explicar o que o texto diz e como ele faz para dizer o que diz, examinando, em primeiro lugar, o seu plano de conteúdo, concebido sob a forma de um percurso global que simula a "geração" do sentido. Ao priorizar o estudo dos mecanismos intradiscursivos de constituição do sentido, a semiótica não ignora que o texto é também um objeto histórico determinado na sua relação com o contexto (tomado em sentido amplo). Apenas optou por olhar, de forma privilegiada, numa outra direção. (MATTE; LARA, 2009, p. 340[1])

Nesse artigo a embalagem será compreendida como um texto, como uma totalidade articulada de sentido, e justamente por analisá-la enquanto texto é que a Semiótica de Greimas foi escolhida e será utilizada como arcabouço teórico-metodológico de análise

O texto, para a teoria de A. J. Greimas, é constituído de dois planos: o plano da expressão e o plano do conteúdo, sendo que estes planos podem interagir de formas diferentes, tendo conformidade entre si ou não. De acordo com Fiorin (2003, p. 78), Hjelmslev distinguiu a semiótica monoplanar e biplanar, que levou a semiótica a acolher esta diferença e criar os sistemas simbólicos e semióticos.

Há, nos sistemas simbólicos, uma correspondência termo a termo entre o plano da expressão e o plano do conteúdo, o que significa que existe uma conformidade total entre esses dois planos. [...] Já nos sistemas semióticos não há uma conformidade entre o plano da expressão e o do conteúdo. (FIORIN, 2003, p. 78)

A partir destes dois sistemas a semiótica cria os sistemas semi-simbólicos, onde a conformidade entre os planos da expressão e do conteúdo se estabelece pela correlação entre categorias dos dois planos (FIORIN, 2003, p. 78).

a semiótica dos sistemas semissimbólicos oferece a possibilidade de recuperar esse diálogo do inteligível com o sensível, ao destacar, na correlação entre as categorias dos planos da expressão e do conteúdo, os mecanismos reveladores da transfiguração das sensações em manifestação sígnica. (TEIXEIRA, 1998, p. 3).

O plano da expressão da visualidade é dividido em quatro categorias do plano da expressão: cromática, eidética, topológica e matérica. Este plano faz parte da semiótica plástica, que parte da materialidade para dar forma ao sentido (TEIXEIRA, 2008, p. 7).

$\mathrm{Na}$ figuratividade, aponta-se a iconicidade e abstração como diretrizes de análise, quanto mais perto da iconicidade, mais o texto remeterá a elementos do mundo percebido, e quanto mais abstrato este for, mais subjetiva é a interpretação do que está sendo representado.

A categoria cromática trata-se da combinação de cores, a categoria eidética diz respeito às formas e linhas, a categoria topológica refere-se à posição e orientação das formas (distribuição) e a categoria matérica, relaciona-se com os aspectos materiais, sua materialidade.

Greimas, como já foi dito, tem como unidade de análise o texto e para ele, a Semântica relativa a esse texto deve ser: (a) gerativa, no qual é possível perceber que diferentes elementos do nível superficial podem significar a mesma coisa num nível mais profundo; (b) sintagmática, no qual analisa-se a produção e a interpretação do discurso e; (c) geral, no qual um único sentido pode ser manifestado por diferentes formas (FIORIN, 2011, p. 16).

O plano conteúdo é construído pelo percurso gerativo do sentido, "que mostra como se produz e se interpreta o sentido, num processo que vai do mais simples ao mais complexo" (FIORIN, 2011, p. 20). Este percurso passa por três patamares: o nível fundamental, o nível narrativo e o nível 
discursivo.

Segundo Fiorin (2011), o nível fundamental é a base da construção de um texto, onde há a categoria semântica de oposição, mas com traços em comum, para se estabelecer uma diferença e uma contrariedade. O nível narrativo é onde se situa a narratividade, que é, segundo Fiorin (2011, p. 27), "uma transformação situada entre dois estados sucessivos e diferentes. Isso significa que ocorre uma narrativa mínima, quando se tem um estado inicial, uma transformação e um estado final". Este nível é tradicionalmente formado pela sequência canônica, que é dividida em quatro etapas: manipulação, competência, performance e sanção. O nível discursivo converte a forma abstrata, do nível narrativo, em algo mais concreto. É nesse patamar que se "produz as variações de conteúdos narrativos invariantes". (FIORIN, 2011, p. 41)

Ao partir dessa definição apresentada de narratividade como transformação entre estados sucessivos, é fácil entender a narratividade em um conjunto de produções humanas: nos filmes, nos livros e nas peças de teatro seus personagens, sempre mudam ao longo da trama, sofrem alguma transformação. O início da história nunca é igual ao seu final. Mas se a proposta da Semiótica de Greimas é a de estabelecer um modelo geral da construção do sentido, então essa definição de narratividade precisa funcionar para uma grande variedade de textos que, às vezes, não são tão explícitos como os exemplos dados. Se uma embalagem também é uma totalidade de sentido, com a qual há uma interação muito frequentemente no cotidiano, ela precisa obedecer à postulação geral da Semiótica e ser dotada de um nível narrativo. Para testar essa hipótese, escolheu-se a embalagem conceitual Hexagonal Honey como estudo de caso. A partir da análise de seu plano da expressão e do seu plano do conteúdo, buscou-se compreender se e como uma embalagem é capaz de apresentar uma narratividade, e de que maneira esse nível narrativo integra-se na produção global de sentido do texto-embalagem.

\section{Análise Semiótica}

A análise foi realizada através das imagens de apresentação do produto individual (Fig. 1) e de sua composição modular (Fig. 2), já que este ainda não foi fabricado. Estas imagens foram retiradas do portfólio do designer que criou a embalagem do Hexagonal Honey. 
Figura 1. Imagem da embalagem conceito de mel.

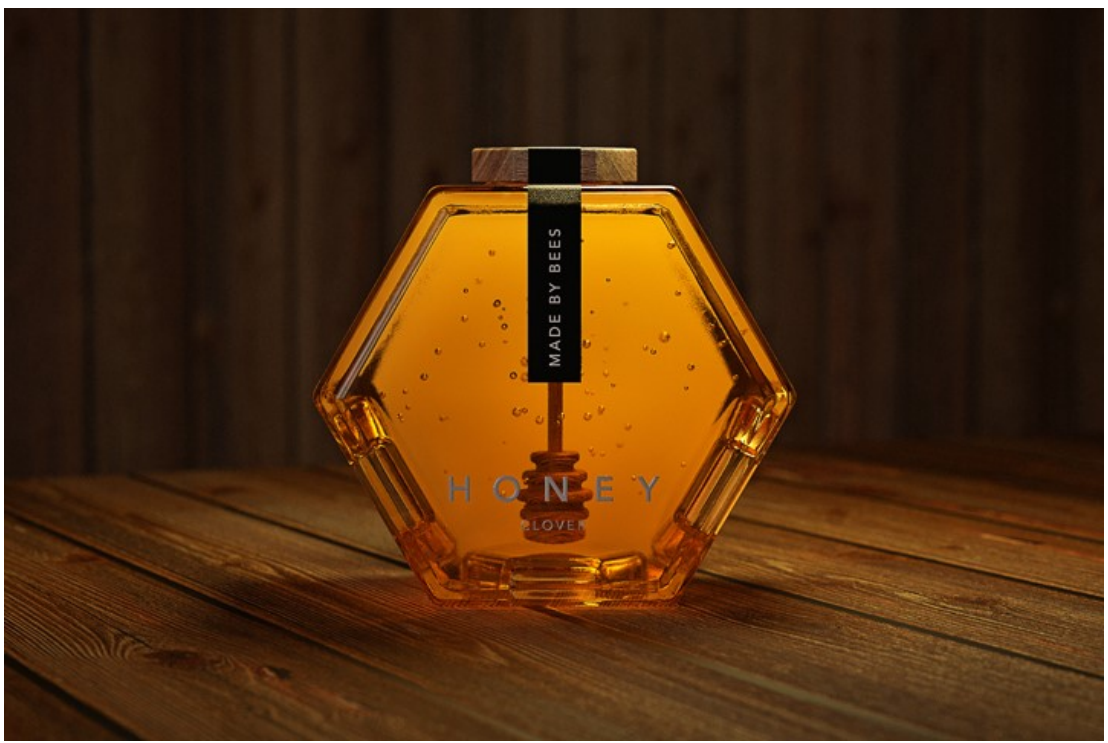

Fonte: https://www.behance.net/gallery/11750165/Hexagon-Honey

Figura 2. Composição modular da embalagem conceito de mel

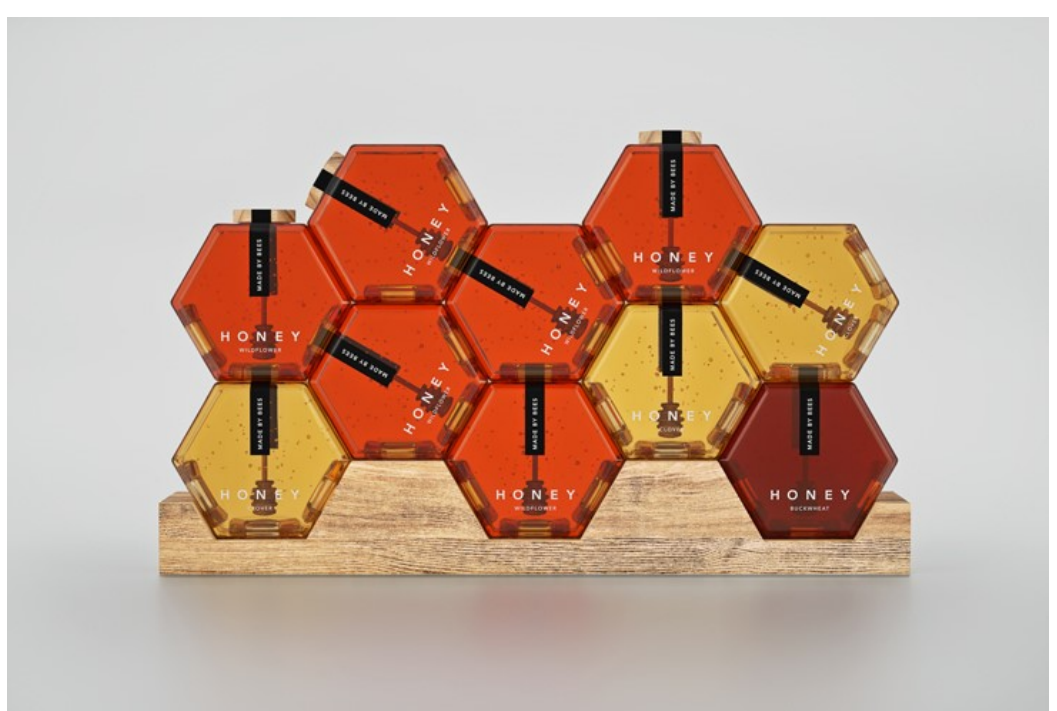

Fonte: https://www.behance.net/gallery/11750165/Hexagon-Honey

A partir da observação criteriosa das imagens acima postas, metodologicamente procedemos à análise do seu plano da expressão e, em seguida, do seu plano do conteúdo. 


\title{
2.1 Plano de Expressão
}

Tabela 1. Análise do plano de expressão da embalagem individual e das embalagens em composição.

\begin{tabular}{|c|c|c|c|}
\hline \multicolumn{2}{|l|}{ Categorias } & \multirow{2}{*}{$\begin{array}{l}\text { Embalagem } \\
\text { Icônica } \\
\text { (alvéolo) }\end{array}$} & \multirow{2}{*}{$\begin{array}{l}\text { Embalagem em composição } \\
\begin{array}{l}\text { Icônica } \\
\text { (colmeia) }\end{array}\end{array}$} \\
\hline Semiótica Figurativa & Icônico/ Abstrato & & \\
\hline \multirow[t]{4}{*}{ Semiótica Plástica } & Cromática & $\begin{array}{l}\text { puro } \\
\text { brilhante } \\
\text { não saturado } \\
\text { claro } \\
\text { natural }\end{array}$ & $\begin{array}{l}\text { mesclado* } \\
\text { brilhante } \\
\text { não saturado } \\
\text { claro } \\
\text { natural }\end{array}$ \\
\hline & Eidética & $\begin{array}{l}\text { geométrico } \\
\text { retilíneo } \\
\text { diagonalidade } \\
\text { pontiagudo } \\
\text { limpo } \\
\text { harmonioso } \\
\text { simétrico }\end{array}$ & $\begin{array}{l}\text { geométrico } \\
\text { retilíneo } \\
\text { diagonalidade } \\
\text { pontiagudo } \\
\text { limpo } \\
\text { harmonioso } \\
\text { assimétrico* }\end{array}$ \\
\hline & Topológica & $\begin{array}{l}\text { baixo } \\
\text { central } \\
\text { largo }\end{array}$ & $\begin{array}{l}\text { baixo } \\
\text { periférico* } \\
\text { largo }\end{array}$ \\
\hline & Matérico & $\begin{array}{l}\text { rígido } \\
\text { quente } \\
\text { resistente } \\
\text { leve } \\
\text { robusto } \\
\text { sem relevo } \\
\text { liso }\end{array}$ & $\begin{array}{l}\text { rígido } \\
\text { quente } \\
\text { resistente } \\
\text { leve } \\
\text { robusto } \\
\text { sem relevo } \\
\text { liso }\end{array}$ \\
\hline
\end{tabular}

Fonte: próprio autor.

A embalagem (Fig. 1) é icônica pelo fato de representar um alvéolo do favo de mel de forma que o reconhecimento é imediato. Já a composição de embalagens (Fig. 2) por encaixes mostra uma similaridade com a realidade da organização da colmeia, o que a torna icônica também.

\begin{abstract}
A leitura iconizante pressupõe um significante e um significado que produzirá um signo passível de interpretação em que esses objetos visuais assumem diferentes graus de densidade dos traços e de organização visuais. A variação desses traços visuais permitirá a leitura do objeto que se aproxima do mundo natural, assumindo uma leitura figurativa. Todavia, quanto mais os traços visuais, constituintes do conjunto dos formantes figurativos, se afastarem de uma representação dos objetos do mundo natural, mais a leitura das figuras será de difícil reconhecimento, constituindo, portanto, uma maior abstração desse objeto. Por conseguinte, podemos dizer que a abstração e a iconicidade representam graus variáveis de leitura figurativa e que não são duas maneiras fundamentalmente diferentes de pintar. (JOÉ, 2008, p. 02)
\end{abstract}

Segundo Greimas (1984, p.29, apud JOÉ, 2008, p. 02) a interpretação de um objeto semiótico depende da leitura que o constrói, pois quando o objeto se afasta da imagem do mundo figurativizado, caminha para a ponta oposta da mesma escala representativa de abordagem visual, apresentando uma desconstrução da iconicidade que ruma à leitura estética. Portanto, um objeto 
terá "efeitos de sentido", enquanto objeto significante segmentável passível de ser analisado em partes menores, constituintes de um todo.

Na escala cromática, o produto é puro por mostrar a cor amarela, já a embalagem em composição é mesclada, pois mostra vários tons de amarelo. Tanto a embalagem, quanta a composição, são brilhantes por serem feitas de vidro transparente, que é um material que possui brilho. Todos os tons dos diferentes tipos de mel são não saturados, já que são tons mais claros e mais escuros que o tom de amarelo saturado. As cores dos diferentes tipos de mel são claras e naturais, pois a cor da embalagem vem somente do conteúdo, que é natural, não sofrendo nenhuma mudança artificial. Na dimensão eidética, o produto é classificado como geométrico, retilíneo, diagonal e simétrico por representar um alvéolo (unidade do favo-de-mel), que tem o formato hexagonal. Já a embalagem em composição não é simétrica por causa do sistema de encaixe. Tanto a embalagem, quanto a composição são pontiagudas, já que possuem a forma hexagonal, que possui 6 pontas (Fig. 3). Por ser uma embalagem minimalista, a forma dela é limpa e harmoniosa.

Figura 3. Forma hexagonal da embalagem.

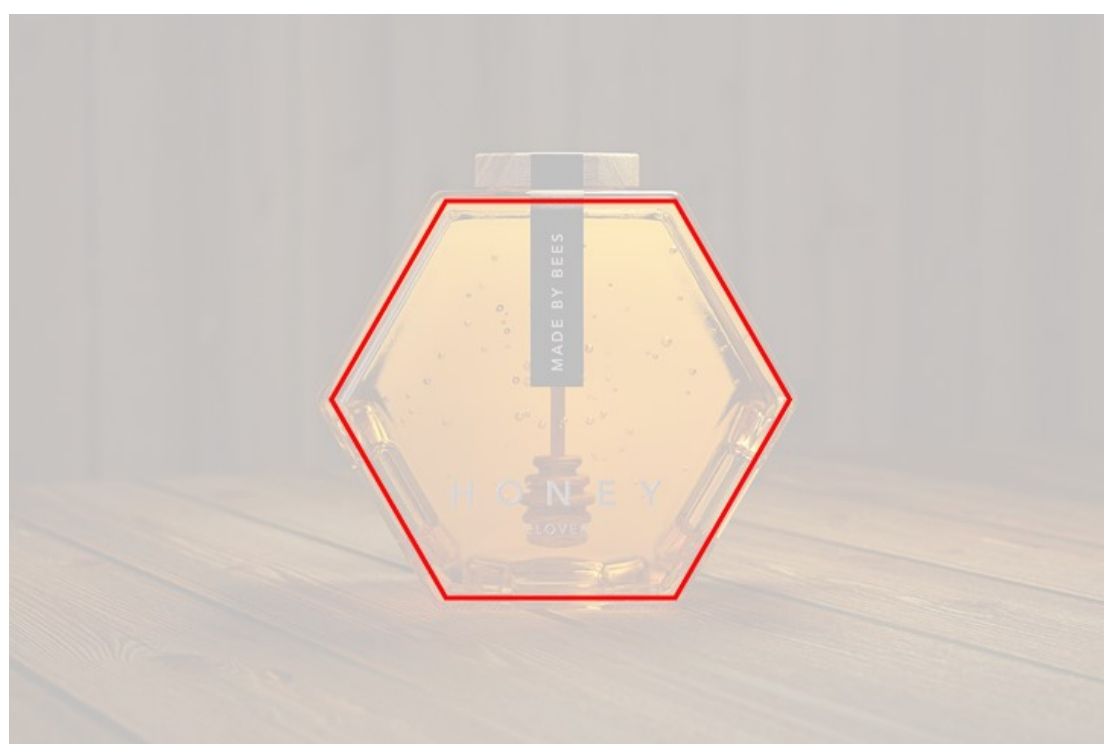

Fonte: https://www.behance.net/gallery/11750165/Hexagon-Honey e adaptado pelo próprio autor.

Na dimensão topológica, tanto a embalagem, quanto a composição foram caracterizadas como baixas e largas, porém possuem uma diferença, já que a embalagem, por ser simétrica, é central e a composição, por ser assimétrica, é periférica.

Na dimensão matérica, foi analisado que a embalagem é feita de material rígido e resistente, que passa uma sensação de aquecimento (o calor se dá pelo uso da madeira e pela coloração âmbar do próprio produto que a transparência do vidro nos deixa ver) e leveza. Por ser uma embalagem minimalista e com pouca informação, esta não possui relevo.

\subsection{Plano de Conteúdo}

\subsubsection{Nível Fundamental}

Há nesse texto uma oposição entre o mel, que é algo 100\% natural e o consumo de mel, que 
é algo cultural. A categoria semântica, neste caso é /natureza/ vs. /cultura/, estes termos opostos têm em comum a transformação, e isso faz com que seja estabelecida a contrariedade, já que os termos estão em relação de pressuposição recíproca. A transformação torna-se algo em comum, pois a natureza e a cultura alteram o mundo, porém fazem isso de formas diferentes, já que há as alterações sofridas pelo mundo natural, no qual o ser humano não intervém, e as transformações culturais.

Cada um dos elementos da categoria semântica de base de um texto recebe a qualificação semântica /euforia/ vs. /disforia/ (FIORIN, 2011, p. 23). Pode ser eufórica, onde é dado um valor positivo ou disfórica, que é visto com um valor negativo. No caso da embalagem do Hexagonal Honey, a natureza é eufórica, porque esta está sendo enaltecida pela embalagem, lembrando o consumidor de onde vem o mel, já a cultura é disfórica, pois é ela que aliena o consumidor, fazendo com que este não saiba como o mel é produzido.

A sintaxe do nível fundamental abrange duas operações: a negação e a afirmação (asserção). No caso deste texto, ocorre a seguinte relação: afirmação da cultura, negação da cultura, afirmação da natureza. A afirmação da cultura é no consumo de mel pelos seres humanos, a negação da cultura se dá na percepção de que a embalagem é um favo-de-mel e a afirmação da natureza, na realização de que o mel é um produto que vem da natureza.

\subsubsection{Nível Narrativo}

Se em um nível fundamental já encontramos uma oposição semântica que dava conta da transformação do mundo, ou seja, a oposição semântica entre o mel (natural) e sua apropriação e consumo pelo homem (cultural), não é difícil delinear a partir daí a narrativa que se depreende da análise dessa embalagem. A narratividade deste texto se dá com a mudança do estágio inicial, que é a falta do produto, até o estágio final, que é a obtenção do produto.

A sequência canônica deste texto se inicia pela manipulação, onde o sujeito 2, manipulado, é induzido a fabricar o produto de interesse do sujeito 1 , manipulador. Fiorin nos explica as estratégias de manipulação da seguinte maneira:

\footnotetext{
Há inúmeros tipos de manipulação: o pedido, a ordem, etc. Vamos descrever apenas os quatro tipos mais comuns. Quando o manipulador propõe ao manipulado uma recompensa, ou seja, um objeto de valor positivo, com a finalidade de levá-lo a fazer alguma coisa, dá-se uma tentação. Quando o manipulador o obriga a fazer por meio de ameaças, ocorre a intimidação. Se o manipulador leva a fazer manifestando um juízo positivo sobre a competência do manipulado, há uma sedução. Se ele impele à ação, exprimindo um juízo negativo a respeito da competência do manipulado, sucede uma provocação. (FIORIN, 2011, p. 30)
}

Isto ocorre de duas formas: por intimidação, onde o sujeito 1 (que será figurativizado, no discurso, pelo "homem") captura o sujeito 2 (em um patamar discursivo, a "abelha") e provêm o substrato necessário para a fabricação do produto.; e por tentação, quando o sujeito 1 oferece o substrato que o sujeito 2 precisa para fabricar o produto.

A segunda etapa é quando o sujeito 2 adquire a competência, que no caso é o substrato necessário.

Depois de adquirir a competência, o sujeito 2 realiza a performance, onde ocorre a produção e a efetivação do objetivo inicial, ocorrendo a conjunção com seu objeto de valor. $O$ sujeito 2 recebe o objeto modal do sujeito 1 e fabrica o objeto de valor, que é o produto. Vejamos a explanação de 
Fiorin sobre os objetos modais e de valor:

\begin{abstract}
A semântica do nível narrativo ocupa-se dos valores inscritos nos objetos. Numa narrativa, aparecem dois tipos de objetos: objetos modais e objetos de valor. Os primeiros são o querer, o dever, o saber e o poder fazer, são aqueles elementos cuja aquisição é necessária para realizar a performance principal. Os segundos são os objetos com que se entra em conjunção ou disjunção na performance principal. (FIORIN, 2011, p. 36)
\end{abstract}

A sanção positiva ocorre no armazenamento do produto pelo sujeito 2 . Esse armazenamento no local apropriado é justamente o que o design da embalagem mostra, então essa embalagem remonta, por meio da explicitação da etapa da sanção, todo o processo de fabricação do produto.

Segundo Fiorin (2011, p. 31), é na sanção que o ocorre a constatação de que a performance se realizou e, por conseguinte, o reconhecimento do sujeito que operou a transformação.

\title{
2.2.3 Nível Discursivo
}

No nível discursivo, as formas abstratas do nível narrativo são revestidas de termos que lhes dão concretude. No caso deste texto, o discurso conta a história da produção de mel.

Os apicultores capturam as abelhas, para que estas produzam mel. Para incentivar a produção, eles provêm um local com árvores que possuam flores, de onde as abelhas, atraídas pelo néctar destas, recolherão o néctar para levá-lo de volta para a colmeia, onde este será transformado em mel pelas próprias abelhas, que será armazenado no favo-de-mel.

A debreagem deste texto, que é a projeção no enunciado das pessoas, tempo e espaço da enunciação, mostra que o discurso é distante, pois fala-se de terceiros, que nesse caso é a abelha e apicultor; num tempo passado, que é o momento da produção de mel e; em um outro local, que é o campo, onde ocorre a produção de apicultura, longe de onde o consumidor de mel está comprando ou utilizando esta embalagem.

\section{Conclusão}

Ao final da análise do plano de expressão e de conteúdo pode-se concluir que há uma narrativa na embalagem. Não apenas identifica-se uma transformação de estado, como conseguimos mesmo delinear as quatro etapas do percurso narrativo canônico, ou seja, a mesma estruturação narrativa que encontramos em outros tipos de textos como os contos, romances, filmes, histórias em quadrinhos etc.

A iconicidade da embalagem faz com que a narratividade venha quase que instantaneamente na mente do enunciatário. A embalagem no formato do alvéolo do favo-de-mel e a cor natural e característica do mel instigam o enunciatário a lembrar de onde vem o produto que é consumido e o levam a essa realidade muitas vezes distante da sua, se imaginamos um ambiente urbano de consumo.

A embalagem, e principalmente as embalagens em composição, atraem o consumidor por fazer este se sentir parte da produção de mel, como se ele estivesse pegando o mel direto da fonte (favo-de-mel).

Esta análise demonstrou, que apesar de não ficar tão claro em um primeiro olhar, o design de embalagem pode apresentar uma complexidade semântica e isto faz com que o designer possa construir narrativas a partir do design de embalagem e a semiótica pode fornecer um aparato conceitual para analisar essas narrativas construídas pelas embalagens. Estudos futuros, analisando 
outros tipos de embalagem podem encontrar ainda regularidades e diferenças entre as várias narrativas construídas pela prática do packaging.

\section{Referências}

ARBUZOV, M. Honey Concept. Disponível em:

<https://www.behance.net/gallery/11750165/Hexagon-Honey >. Acesso em: 27 out 2017.

FIORIN, J. L. Elementos de análise do discurso. 15 ed. São Paulo: Contexto, 2011.

FIORIN, J. L. Três questões sobre a relação entre expressão e conteúdo. Itinerários, Araraquara, n. especial, p. 77-89, 2003.

GREIMAS, Algirdas Julien. "Semiótica figurativa e semiótica plástica". no4. In: Significação, Araraquara, 1984.

JÓE, Márcia Maria Sant'Ana. Escrituras de Drummond: Arte em exposição (questões de iconicidade e abstração). Estudos Semióticos. [online] Disponível na Internet via WWW.URL: http://www.fflch.usp.br/dl/semiotica/es. Editor Peter Dietrich. Número 4, São Paulo, 2008. Acesso em "20/03/2018".

MATTE, A.C.F.; LARA, G. M. P. Um panorama da semiótica greimasiana. Alfa, São Paulo, v.53, n.2, p.339-350, 2009.

PELLEGRINO, L. Embalagem. Disponível em: <http://www.abre.org.br/setor/apresentacao-dosetor/a-embalagem/>. Acesso em: 02 nov 2018.

RAMALHO, S. Imagem também se lê. São Paulo, Rosari, 2005.

TEIXEIRA, L. Leitura de textos visuais: princípios metodológicos. In: BASTOS, Neusa Barbosa (org.). Língua portuguesa: lusofonia - memória e diversidade cultural. São Paulo: EDUC, 2008. p.299-306 